\title{
More Flowerpots, Less Smoking?
}

\section{David Sharp}

The ancient Romans numbered among their many deities lares, household gods with a remit extended to whole cities, according to some authorities. The European region of the World Health Organization, possibly using the well-established practice of thinking of a happy acronym first and only then deciding what it should stand for, has a project called LARES. The Large Analysis and Review of European housing and health Status, based at the WHO European Centre for Environment and Health in Bonn, Germany, is a massive program in 21 parts that focuses variously on cold, noise, mental health, and pests, for example, and includes tobacco. $^{1,2}$ The smoking project is led by Rebecca Miles from Florida State University, Tallahassee, and her findings were released in August, 2006. ${ }^{3}$

You might expect research involving tobacco and the home to have an emphasis on environmental exposure (passive smoking), but Dr. Miles' approach is different, for she looks at the relationship between the smoking habit and something called "neighborhood disorder" as reflected in two proxies for antisocial behavior (graffiti and litter) and in the use of plants to decorate the exteriors of homes. She also looks at residents' fear of walking home at night. All this is in seven urban settings in traditional western Europe and in the former eastern sector, data for rural communities being excluded. The locations are Angers, Bonn, Forli, and Geneva, and Bratislava, Budapest, and Vilnius. To summarize Miles' findings as showing that people living in urban areas with no litter or graffiti and geraniums on balconies are less likely to smoke than those residing in untidier parts of a city-and that is what she did find-sounds like a glimpse of the obvious. After all, we already know that socioeconomic deprivation is associated with an increased likelihood of cigarette use. ${ }^{4,5}$ However, this research has made use of increasingly complex statistical models that allowed for the many possible confounders, income and education included. An odds ratio for smoking of 1.64 for high as against low neighborhood-disorder scores is the main effect reported, but a striking increase persisted however the analysis was done. Little of this can be explained by perceived safety, by the way. The effect appears more striking for men than for women, a result which, as Miles notes, is not consistent with UK studies on smoking and deprivation.

If people are willing to spend up to one-fifth of their already low incomes on cigarettes, ${ }^{4}$ it is going to take a whole lot more than distributing flowerpots, compost, and a few seeds to make a difference to a public health scourge that, on one widely quoted prediction, ${ }^{6}$ at present rates, will kill one billion people before the 21 st century is out. As Miles points out, improvements in the urban environment are worth doing even without the health argument, so it remains to

Sharp is a contributing editor to The Lancet, London, UK.

Correspondence: David Sharp, 2 Iron Mills, Minchinhampton GL6 9AL, UK. (E-mail: david@ sharp.4857.fsnet.co.uk) 
be seen how politically persuasive this LARES evidence will prove. Nonetheless, urban clean-ups and botanical adornment are not expensive interventions, and if, as a consequence, local communities did smoke less, that could throw light on what sustains the habit besides the direct health and economic benefits. Also, the paper reminds us that smoking prevention strategies, so often aimed at the individual, may need community and environmental dimensions as well, and these take us well beyond the usual activities of the hospital-based respiratory clinic or family doctor's office.

\section{REFERENCES}

1. World Health Organization European Region. Large Analysis and Review of European housing and health Status: preliminary overview June 2006. Available at: http:// www.euro.who.int/Document/HOH/LARES_results.pdf. Accessed on: September 9, 2006.

2. Bonnefoy X, Braubach M, Moissonnier B, Kubanychbek M, Robbel N. Housing and health in Europe: preliminary results of a pan-European study. Am J Public Health. 2003; 93:559-563.

3. Miles R. Neighborhood disorder and smoking: findings of a European urban survey. Soc Sci Med. 2006;63:2464-2475. http://dx.doi.org:10.1016/j/socscimed.2006.06.011.

4. Haustein KO. Smoking and poverty. Eur J Cardiovasc Prev Rehabil. 2006;13:312-318.

5. Crosier A. A rapid mapping study of smoking projects and services targeted at people living on low income and/or minority ethnic groups: report to the Health Development Agency February 2001. Available at: http://www.ash.org.uk/html/policy/mapping.html. Accessed on: September 9, 2006.

6. Rosner SA, Stampfer MJ. The heart-breaking news about tobacco: it's all bad. Lancet. 2006;368:621-622. 